\title{
CORPOS ESCRAVIZADOS: QUE HISTÓRIAS CONTAM?
}

\author{
Iamara da Silva Viana*
}

\section{Resumo:}

O presente artigo apresenta como cerne o corpo escravizado no início do século XIX por meio do discurso do médico francês JeanBaptiste Alban Imber, formado em Montpellier, que chegou ao Brasil em 1831. Nele observaremos como referida história pode ser construída e quais as preocupações deste médico relativas ao momento em que o debate sobre o fim do Tráfico Transatlântico entra em pauta. O corpo escravizado, força de trabalho utilizado nos plantéis do principal produto de exportação a partir dos anos 1830 - o café -, pode ser pensado como "uma realidade biopolítica" e a medicina "uma estratégia biopolítica" segundo Foucault (1979: 80), e a partir destas definições desenvolveremos nossas reflexões.

Palavras-chave: corpo escravizado; medicina; escravidão; discurso médico.

\begin{abstract}
:
This article presents as its main subject enslaved body at the beginning XIX century, a story told by the French doctor Jean-Baptiste Alban Imber, graduated from Montpellier, who came to Brazil in 1831. It will show how this story was created and the worries of this doctor concerning the discussions about the ending of transatlantic slave trade. In enslaved body, the workforce used by the main product exported in the 1830's - coffee-, may be seen as "bio-politics reality" and medicine as "biopolitics strategy" according Foucault (1979:80) and with these definitions our reflections will be developed, part of the research in process.
\end{abstract}

Keywords: enslaved Body; medecine; slavery; medical discourse.

...Pois o corpo tem uma história. A concepção do corpo, seu lugar na sociedade, sua presença no imaginário e na realidade, na vida cotidiana e nos momentos excepcionais sofreram modificações em todas as sociedades históricas. Jacques Le Goff.

O corpo tem uma história, dessemelhantes histórias, em diferentes tempos e espaços. E, a partir desse pressuposto, apresentamos neste artigo, reflexão que oferece uma das muitas possibilidades de pensar o corpo escravizado no início do século XIX. Tomamos por base as proposições de um médico francês, Jean-Baptiste Alban Imbert. Formado em Montpellier,

\footnotetext{
* Doutoranda em História Política pela Universidade do Estado do Rio de Janeiro/École des Hautes Études en Sciences Sociales, Paris. Professora do Quadro Complementar do Departamento de História da Pontifícia Universidade Católica do Rio de Janeiro/PUC-Rio. Este artigo é parte de pesquisa do doutorado em desenvolvimento. E-mail: ia.sviana@gmail.com.
} 
chegou ao Império do Brasil em 1831, ano da promulgação da primeira lei que impediria o tráfico transatlântico de escravos. Imbert foi o primeiro médico a ter seu diploma reconhecido e confirmado pela Academia Imperial de Medicina do Rio de Janeiro, seguindo o protocolo da época, a Lei de 03 de outubro de 1832, que daria "nova organização às actuais Academias Medico-cirurgicas das cidades do Rio de Janeiro, e Bahia”. Apresentou, para tanto, em 1834, a tese As Hemorrhoidas. Em 15 de outubro de 1835, foi aceito como membro titular da Academia Brasileira de Medicina. Da mesma forma, fora membro efetivo das Sociedades Auxiliadoras das Industrias Nacionais e Literatura do Rio de Janeiro (SAIN).

Jean-Baptiste Alban Imbert nascera numa família tradicional e, ainda na França, foi prefeito, entre os anos de 1820 e 1824 na Comuna 83 de Beausset $(\text { le })^{1}$, membro honorário da Sociedade Real de Medicina de Marseille e Cirurgião Ajudante Maior da Marinha Imperial Francesa. No Rio de Janeiro três anos após sua chegada, 1834, escreveu o Manual do Fazendeiro ou Tratado Doméstico sobre as Enfermidades dos Negros, generalizado às necessidades médicas de todas as classes. Cinco anos mais tarde, em 1839, publicou a segunda edição, por ter sido a primeira, segundo suas próprias palavras, um grande sucesso (IMBERT, 1839: p. XVI). Fora aumentada em um volume e publicada pela Tipografia Nacional do Rio de Janeiro, composta por uma introdução, dez títulos e quarenta capítulos, todos organizados por seções ou classes, totalizando 688 páginas.

A obra poderia ser adquirida na casa do autor, à rua da Quitanda, número 61; na casa de Laemmert, livreiro, mesma rua, número 77; e também na de Agostinho de Freitas Guimarães, rua do Sabão, número 26 (IMBERT, 1839). Outras obras foram escritas e publicadas pelo médico: Ensaio higiênico sobre o clima do Rio de Janeiro (1837); O Charlatanismo: uma palavra sobre o charlatanismo e os charlatães (1837) e o Guia médico das mães de família ou A infância considerada na sua hygiene, suas moléstias e tratamentos (1843). Na Academia, apresentou duas memórias: Quelques réflexions sur la sensibilité e Des consultations clinique de Ce qu'ells sont à Rio de Janeiro et de ce qu'elles devraient être. Segundo Carlos da Silva Araujo (1979: p. 224), Imbert exerceu a medicina no Rio de Janeiro até o ano de 1843. Contudo, seu interesse era estudar as "doenças populares" e, como o próprio título do Manual sugere, as "enfermidades dos negros", dos escravizados. Nesse sentido, o corpo, para o médico, adquire relevância, posto que o conhecimento sobre ele permitiria realizar "boa compra" ou intervir, em caso de doença.

\section{O Corpo}

1 Disponível em http://www.francegenweb.org/mairesgenweb/resultcommune.php?id=23443. Acesso em: 15 jun. 2013.

Dossiê Transversos: O Corpo na História e a História do Corpo, Rio de Janeiro, v. 05; n. 05; Ano 02. dez. 2015. 
As construções relativas ao corpo foram distintas, como aponta a epígrafe. $\mathrm{Na}$ Antiguidade Clássica, era considerado de forma positiva. Na Idade Média durante longo período, fora condenado como o responsável por pecados cometidos pelos homens, devendo, por isso, ser punido, para que a alma - o elemento mais importante considerado pela Igreja Católica naquele tempo histórico - pudesse ser salva. O Renascimento, numa redescoberta de obras e autores da Antiguidade Clássica (AZEVEDO, 1999: p. 387), apresenta um corpo a ser admirado, o homem passa a ser o centro dos pensamentos, aquele que poderia dominar a natureza, o que poderia significar a própria natureza humana.

Ao refletir sobre a "história da violência nas prisões", Foucault (2011: p. 28) assinalou que muitos historiadores abordaram a história do corpo, tendo sido este objeto de diferentes estudos, todos concentrados na questão biológica e no lugar a ser ocupado na "história das sociedades”. O biológico é parte constante do estudo do corpo, não devendo, portanto, ser desconsiderado. Afinal, suas funções são fundamentais para a própria sobrevivência da espécie. É possível, no entanto, considerar somente este fator ao analisá-lo?

Michel Foucault (2011) nos ajuda a responder a questão, apontando que, para além do biológico, "o corpo também está diretamente mergulhado num campo político; as relações de poder têm alcance imediato sobre ele; elas o investem, o marcam, o dirigem, o supliciam, sujeitam-no a trabalhos, obrigam-no a cerimônias, exigem-lhe sinais” (p. 28). Sua reflexão inserese no século XVIII, o século das luzes, acerca do suplício imposto ao corpo condenado, que aferia o "pedir perdão publicamente", realizado por meio de rituais específicos, dentre os quais a tortura, definida pelo autor como "economia do castigo" (p. 12-13).

Este corpo era "esquartejado, amputado, marcado simbolicamente no rosto ou ombro, exposto vivo ou morto, dado como espetáculo", sendo, pois, o "alvo principal da repressão penal" (p. 13). O político tinha como meta reprimir o condenado, além de obedecer à vontade do rei e mostrar à sociedade - com os seus diferentes grupos - as sanções possíveis para os crimes cometidos. Alguns grupos desta, entretanto, nem sempre concordava com tais punições, o que demonstra resistência às determinações reais, sendo, posteriormente, importante instrumento de transformação. Em outras palavras, a punição ao corpo condenado fora revista e modificada ao longo de muitos anos na França (FOUCAUT, 2011: p. 13) ${ }^{2}$.

Embora o objeto de estudo de Michel Foucault seja diferente do aqui apresentado, suas reflexões nos apresentam possibilidades de pensar o corpo escravizado no início do século XIX, a

2 Michel Foucault, em Vigiar e Punir, descreve o processo das modificações que ocorreram na forma de punir os condenados na Europa de forma geral, e, na França de modo específico.

Dossiê Transversos: O Corpo na História e a História do Corpo, Rio de Janeiro, v. 05; n. 05; Ano 02. dez. 2015. 
partir do discurso de Jean-Baptiste Alban Imbert, como sublinhado acima. Esse corpo escravizado, tão afeito a doenças - segundo o olhar de Imbert -, era considerado um bem semovente, contraposto às raízes e bens imóveis. Uma categoria jurídica que remontava ao direito romano e tinha grande segmento nas ordenações Filipinas, bem como na legislação e no direito brasileiros do século XIX. Qualificado dessa forma, num conjunto de bens, no qual o gado era também mencionado, não poderia ser considerado "coisa". A aproximação entre escravo e gado está condicionada ao valor de uso de ambos no trabalho, o que era percebido pelos proprietários, atendendo às suas necessidades nas fazendas de café ${ }^{3}$. Tal produto "se alastrou pela província do Rio de Janeiro, nas primeiras três décadas” do século XIX (SALLES, 2008: p. 139). As principais lavouras encontravam-se "nas regiões de Vassouras, Valença, Resende e São João Marcos (...)", sendo responsáveis por mais de 30\% do que era produzido mundialmente (MARQUESE, 2010: p. 158). Nessas regiões, encontrava-se o público para o qual Imbert (1839: Prefácio) escrevia: "aos ilustríssimos senhores fazendeiros". Desta feita, o escravizado era propriedade e mão de obra fundamental para a economia do Império do Brasil. Aqui, uma vez mais, concordamos com Foucault (2011: p. 28-29): "este investimento político do corpo está ligado, segundo relações complexas e recíprocas, à sua utilização econômica (...)”.

Nesse sentido, pensamos o corpo como um conjunto, formado pela essência biológica, mas também pelo contexto social e político no qual está inserido, o que permite sua materialidade. Esta pode ser percebida na definição de como o corpo deverá se vestir, se portar, se alimentar, se divertir, que religião seguir. Os diferentes poderes presentes na sociedade escravista imperial podem ser observados nos corpos de escravizados urbanos e rurais: nos ofícios que desempenhavam, em suas roupas e mobilidade - ainda que ínfima - dentro das fazendas e nos espaços urbanos como escravos ao ganho ${ }^{4}$.

As marcas visíveis - observadas nos corpos escravizados em imagens, textos produzidos pelos viajantes e também na escrita médica - e as invisíveis, muitas das quais não puderam ser registradas, contam-nos histórias distintas. Muitos dos que faziam a "Kalunga", travessia de um continente ao outro por meio do mar (SLENES, 1992: p. 53-54) ${ }^{5}$, carregavam consigo sinais impregnados de significados, demarcavam lugares e, principalmente, origens. Este fato, segundo

3 Diccionario da Lingua Portugueza recopilado dos vocabularios impressos até agora, e nesta segunda edição emendado, e muito accrescentado por Antonio de Moraes Silva. Lisboa: Typographia Lacérdina, 1813.

4 Alguns trabalhos recentes refletem sobre o corpo escravizado. Dentre os quais destacamos a tese O Corpo Escravo como objeto das práticas médicas no Rio de Janeiro (1830-1850) de Silvio Cezar de Souza Lima;

$5 \mathrm{Na}$ perspectiva de Robert Slenes, "Kalunga também significava a linha divisória, ou a 'superficie' que separava o mundo dos vivos daqueles dos mortos [...]”. O autor também pontual que estudos mais recentes e densos sobre o termo Kalunga são associados aos bakongo, falantes de kikongo.

Dossiê Transversos: O Corpo na História e a História do Corpo, Rio de Janeiro, v. 05; n. 05; Ano 02. dez. 2015. 
Robert Slenes (1992: p. 56), incidia diretamente na possibilidade de melhores ofícios demarcando hierarquias possíveis - e na concessão de alforria, se crioulos, e não africanos. Outros tantos demonstram que um devido corpo pertencia a um senhor, portanto, propriedade de outrem.

Tais construções corroboram o cuidado exigido pela reflexão e, nesse sentido, destacamos a relevância em observar o tempo e o espaço sobre os quais trataremos. Nossa reflexão insere-se nos anos 1830, ano em que a lei contra o Tráfico Negreiro já estava em pauta e, segundo Sidney Chalhoub (2012: p. 29-30) feita para ser cumprida. O fim do Tráfico Transatlântico, que só ocorrera em meados do século XIX, especificamente no ano 1850, acentuou modificações nos padrões de tratamentos concedidos aos trabalhadores escravizados urbanos e, também, aos que ocupavam as áreas rurais do vasto Império do Brasil. Escravizados doentes ou mortos poderiam não mais ser tão facilmente repostos. Dessa forma, a divulgação das pesquisas médicas, por meio de publicações em revistas especializadas, manuais e teses acadêmicas, demonstravam a tentativa de minimizar perdas consideráveis, no que tange ao patrimônio senhorial e à economia do Estado, mediante o emprego desses saberes.

Além de Imbert, outros médicos publicaram manuais de medicina dirigidos aos seus pares e também aos leigos desde o século XVI. Destacamos os seguintes autores do século XIX: Pedro Luiz Napoleão Chernoviz (1812-1881), Luiz Francisco Bonjean (1808-1892) e Theodoro Langgaard (1813-1883) ${ }^{6}$. David Gomes Jardim - médico brasileiro - defendeu, na Faculdade de Medicina do Rio de Janeiro, a tese A Hygiene dos Escravos, em 1847, onde apontava a sua inexistência como principal causa de mortalidade escrava. Trata-se de obras relevantes para a população que vivia distante da Corte e, portanto, mais vulnerável às diferentes moléstias que assolavam a população negra e não negra.

Refletir sobre o corpo escravizado não é tarefa das mais fáceis. Isso é possível, contudo, devido às mudanças ocorridas na historiografia, a partir da Escola dos Analles, que nos possibilitou pensar objetos diferentes e distantes dos grandes líderes mundiais desde a Antiguidade Clássica. Os cientistas sociais nos apresentam elementos importantes. Segundo José Carlos Rodrigues (2006: p. 50), "estudar a apropriação social do corpo é estrategicamente importante (...) uma vez que ele é sem dúvida o mais natural, o mais concreto, o primeiro e o mais normal patrimônio que o homem possui" e, desta forma, deveria ser pensado como "uma categoria própria, sistematicamente relacionada às outras categorias sociais”. Classificá-lo implica

6 Para maiores informações ver pesquisa realizada por Maria Regina Cotrim em Chernoviz e os manuais de medicina popular no Império. História, Ciência e Saúde-Manguinhos. v. 12 n. 2, Rio de Janeiro mai/ago, 2005.

Dossiê Transversos: O Corpo na História e a História do Corpo, Rio de Janeiro, v. 05; n. 05; Ano 02. dez. 2015. 
reconhecer "o seu lugar próprio", sendo este "o ponto de convergência de fenômenos singulares que põem em relação íntima a natureza orgânica e a natureza social do homem, onde a cultura e a natureza dialogam, onde o grupo e o indivíduo se interpenetram”.

A contribuição da sociologia nos é importante, mas, como historiadores, o tempo e o lugar são relevantes nesta reflexão, como já sublinhado acima. Nesse sentido, os corpos aqui analisados pertencem a uma determinada época com definições políticas, econômicas e culturais específicas. Daí a importância de reconhecer "o seu lugar próprio", no nosso caso, o da escravidão, onde o corpo deixa de ser "o primeiro e o mais normal patrimônio" de um indivíduo. Não sendo proprietário de seu corpo, pertence a outro indivíduo, seu senhor, e sua condição jurídica é a de escravizado. Sendo fundamental no período estudado para a manutenção do Império do Brasil, posto ser a mão de obra das grandes fazendas de café do Vale Paraíba Fluminense, deveria produzir o máximo possível para a manutenção econômica e política do Estado imperial. Isso não seria possível em caso de enfermidades ou altos índices de mortalidade.

Como pensar, todavia, o corpo humano em sua essência? Inequivocamente, o corpo possui uma materialidade, mas provavelmente, o pensamento - elemento que nos difere dos outros animais - possa explicar a historicidade do corpo. O médico francês Jean-Baptiste Alban Imbert (1839) insere outros elementos e, o define como formado pela "matéria e pelo moral", o que constituir-se-iam em duas essências fundamentais para seu bom funcionamento. Tendo o corpo escravizado vindo de uma "parte do mundo, onde a natureza pôs o berço da raça negra, aliás chamada Africana” (IMBERT, 1839: introdução), poderia ela, como região, determinar o moral. Essa parte do mundo tão distante precisaria ser civilizada. Entretanto, para o médico, a "Natureza traçou huma primeira grande divisão creando duas raças de homens que se distinguem pela cor" (IMBERT, 1839: p. XVIII). Em outras palavras, para Imbert, a primeira diferença a ser considerada entre os homens é a raça: negra ou branca.

A história do corpo escravizado pode ser contada por diferentes ângulos. O corpo que se torna escravo, que chega ao porto, corpo que é vendido, comprado ou usado, corpo que foge, que castiga (quando ocupa o ofício de feitor) e é castigado, corpo doente e que é medicalizado. São muitas as possibilidades, afinal, a escravidão no Brasil passou por diferentes momentos e devemos observar as suas peculiaridades. Para Foucault (1979: p. 80) "o corpo foi investido política e socialmente como força de trabalho", sendo ele "uma realidade bio-política" e a medicina "uma estratégia bio-política". E qual seria a realidade para o período estudado, onde o corpo é um bem semovente, propriedade de outrem?

Dossiê Transversos: O Corpo na História e a História do Corpo, Rio de Janeiro, v. 05; n. 05; Ano 02. dez. 2015. 


\section{Corpo e Trabalho}

Segundo Jean-Baptiste Alban Imbert,

A escravidão subsiste pois ainda em grande parte nas Ilhas e no Continente Americano, particularmente no Brasil; mas aqui será incontestavelmente mais doce e mais humana, pois que a difficuldade de dar substituição ao que se possue fará recorrer aos meios os mais convenientes de conservar o que já se tem (IMBERT, 1839: Introdução, XII).

A dificuldade em substituir escravizados doentes, idosos ou falecidos - sublinhamos que o autor escreve em 1839, onze anos antes do fim definitivo do tráfico de africanos - tornara essa substituição mais onerosa, o que não significa afirmar ter sido "mais doce" para com os que já estavam nas senzalas. O comércio escravo ainda persistia, contudo, o valor do bem sofrera aumento considerável, fosse pelas dificuldades impostas pelo tráfico clandestino, fosse pela percepção de senhores que dominavam o cultivo da cana de açúcar nas Províncias do Nordeste, então em decadência. Ponto incontestável para Imber seria “conservar o que já se tem”. Isso poderia sugerir atenção desde o momento da compra, e, não por acaso, ele instruía fazendeiros que dependiam dessa mão de obra a, por meio do corpo, identificar defeitos e características que pudessem ser indícios do desenvolvimento de algumas enfermidades. Assim, em dez de janeiro de 1839, lançara a segunda edição do seu Manual do Fazendeiro ou Tratado Doméstico sobre as Enfermidades dos Negros para que servisse "de guia prudente no tratamento de vossas enfermidades (senhores) ${ }^{7}$, e da de vossos escravos" (IMBERT: 1839, s/p).

O corpo, sendo força de trabalho escravizada, era também "uma realidade bio-política" (FOUCAULT, 1979: p. 80) e deveria manter-se saudável e produtivo pelo maior tempo possível. Imbert, ao analisá-lo, demonstrava preocupação relativa à compra de trabalhadores escravizados que pudessem não desenvolver determinadas doenças, posto que comprometessem a produção nas fazendas. Sua preocupação se revela ao dedicar o Capítulo Primeiro do Título 1 de seu Manual às "Circunstancias a que deve attender toda pessoa que deseja fazer huma boa escolha de escravos”, uma possível estratégia, e logo nas primeiras linhas informa:

\footnotetext{
a venda dos negros entre os particulares, constitue no Brasil hum ramo de commercio mui consideravel. São os escravos como huma mercadoria, que passa de huma mão a outra para o consumo, com a unica differença de reservar-se o comprador, em geral, o direito de fazer examinar sua boa, ou má qualidade, antes de fechar o trato. Recorre-se para este fim a hum Medico, ou Cirurgião, que emitte o seu juízo sobre as qualidades, ou defeitos physicos do negro, juizo que serve de norma no mercado (IMBERT, 1839: p. 1).
}

7 Grifos meus.

Dossiê Transversos: O Corpo na História e a História do Corpo, Rio de Janeiro, v. 05; n. 05; Ano 02. dez. 2015. 
Como já mencionado existe uma relação complexa presente no investimento político do corpo. Um investimento que estabelecia conhecimentos específicos, na perspectiva de Imbert, principalmente sobre o corpo, suas qualidades e defeitos, servindo, pois, como "norma de mercado". E, nesse sentido, o saber médico era fundamental, tendo em vista a importância de avaliar a boa ou má qualidade do escravizado a ser adquirido.

Para Foucault (2011: p. 29), no que tange à questão econômica seria "como força de produção que o corpo é investido por relações de poder e de dominação; mas em compensação sua constituição como força de trabalho só é possível se ele está preso num sistema de sujeição (...); o corpo só se torna força útil se é ao mesmo tempo corpo produtivo e corpo submisso". A historiografia já demonstrara que, na relação escravista, o escravizado não foi vítima nem algoz em tempo integral. Da mesma, forma, apontou os diferentes mecanismos de dominação utilizados, para além da chibata ${ }^{8}$.

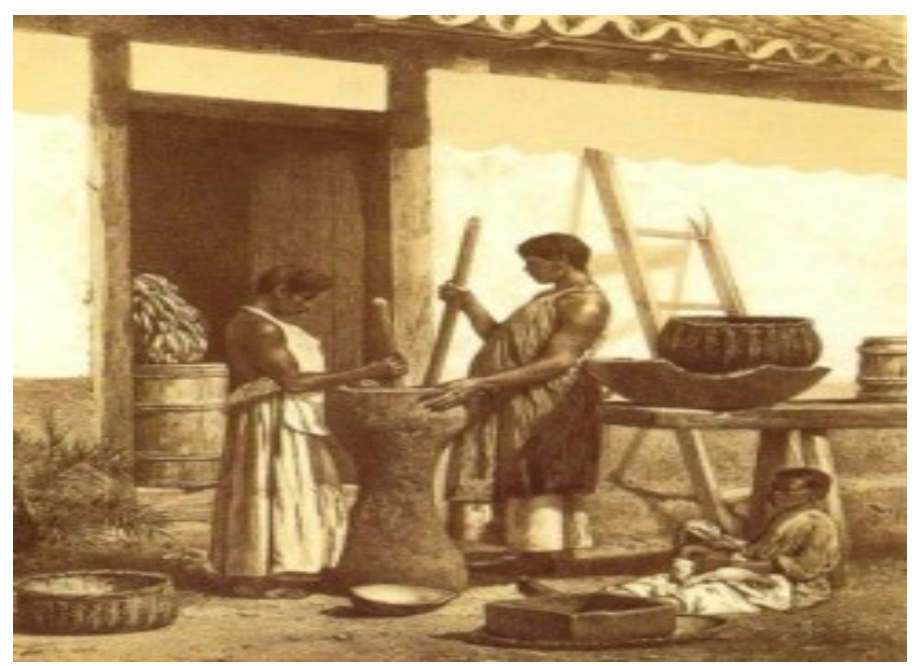

Imagem I: Victor Frond. Socagem do café, 1858.

É como mão de obra, e, que pudesse ser preservado o maior número de anos possíveis em tempos de fim de tráfico, que o corpo escravizado é pensado por Imbert ao instruir seus leitores:

Ainda que, pela mór parte, sejão nossos leitores justos apreciadores do bom, ou do
máo estado de saude do preto, submettido ao seu exame, julgamos todavia que nos
levarão a bem o apresentar-lhes algumas ideias geraes, que sendo attendidas, tornarão o
exame muito mais seguro nos seus resultados; e principiaremos por notar, que cada

8 Para maiores informações ver: SILVA, Eduardo. Negociação e Conflito: a resistência negra no Brasil escravista. São Paulo: Companhia das Letras, 1989; SLENES, Robert. Na Senzala uma Flor; SALLES, Ricardo. E o Vale era o Escravo: Vassouras, século XIX. Senhores e escravos no coração do Império. Rio de Janeiro: Civilização Brasileira, 2008; GOMES, Flávio. Histórias de Quilombolas: mocambos e comunidades de senzalas no Rio de Janeiro, século XIX. São Paulo: Companhia das Letras, 2006. GRAHAM, Sandra Lauderdale. Caetana diz não: histórias de mulheres da sociedade escravista brasileira. São Paulo: Companhia das Letras, 2005.

Dossiê Transversos: O Corpo na História e a História do Corpo, Rio de Janeiro, v. 05; n. 05; Ano 02. dez. 2015. 
clima, cada paiz, imprime a seus habitantes huma physionomia particular, que contribue a fazer reconhecer o lugar do seu nascimento (IMBERT, 1839: 1-2).

O uso do corpo escravizado nos diferentes ofícios aponta-nos a sua necessidade para a economia do Império do Brasil, e as dificuldades muitas vezes encontradas em manter o controle sobre o grande quantitativo de cativos. Nesse sentido, era fundamental conhecer a origem e, principalmente, a constituição física daqueles indivíduos, de sorte que ambos pudessem garantir a maximização da força de trabalho, a permanência do bem e a certeza do lucro. Como estratégia bio-política a medicina colaborava na realização de uma boa compra de cativos, ao apontar possíveis defeitos observados nos corpos colocados à venda. Mormente, se fosse possível prevenir o desenvolvimento de doenças. Escrevendo para um público leigo, Imbert se preocupava em ser claro e objetivo, afinal, nem sempre o fazendeiro poderia contar com a presença de um cirurgião no momento de efetuar um negócio. E quais negros seriam os melhores a serem adquiridos?

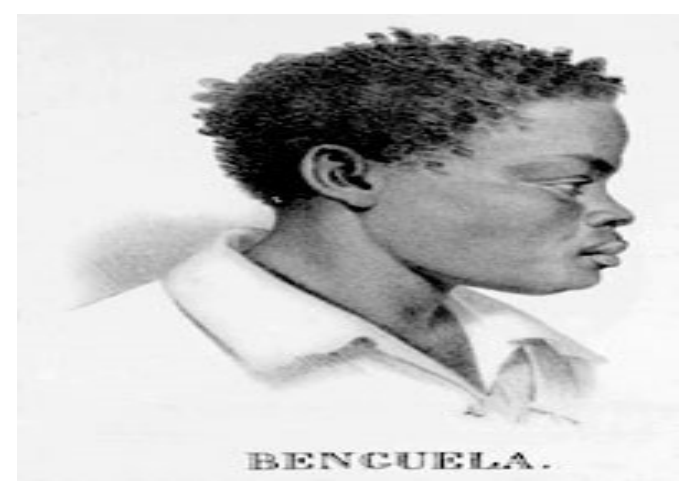

Imagem II: Negro Benguela. Litografia: Johann Moritz Rugendas, 1835. Disponível em: http://www.camaracampos.rj.gov.br/tp-cultura/exposicao-escravidao-no-brasil/

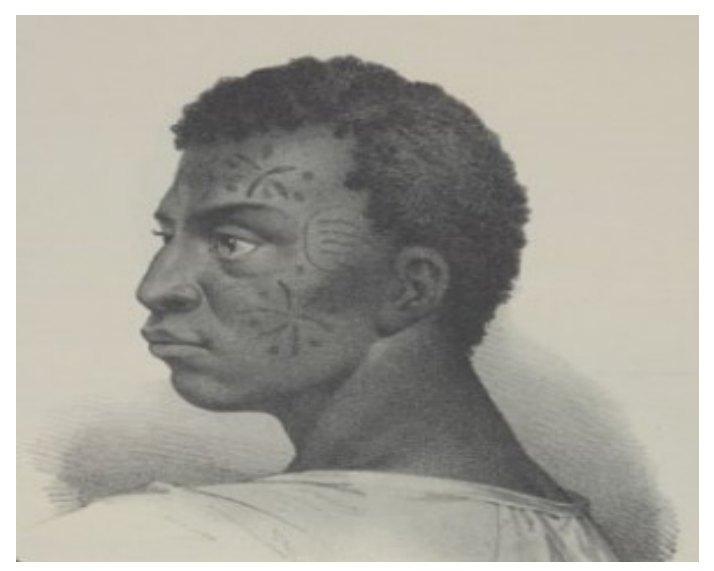

Imagem III: Negro Mozambique: Litografia: Johann Moritz Rugendas, 1835.

Disponível em: http://www.camaracampos.rj.gov.br/tp-cultura/exposicao-escravidao-no-brasil/

Dossiê Transversos: O Corpo na História e a História do Corpo, Rio de Janeiro, v. 05; n. 05; Ano 02. dez. 2015. 


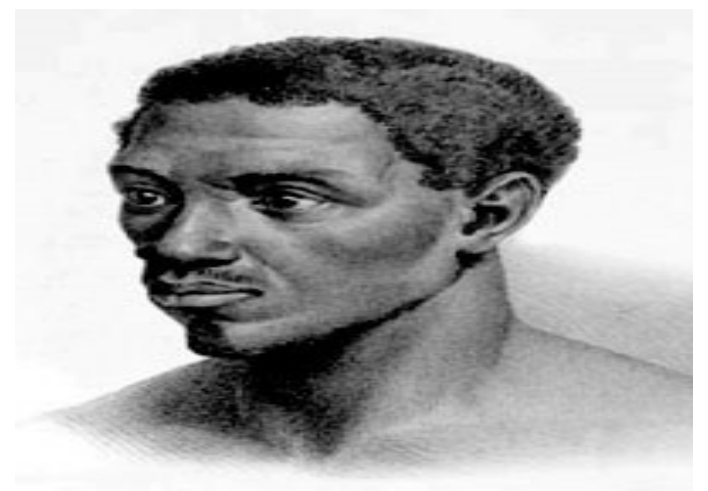

ANGOI.A.

Imagem IV: Negro Angola. Litografia: Johann Moritz Rugendas, 1835.

Disponível em: http://www.camaracampos.rj.gov.br/tp-cultura/exposicao-escravidao-no-brasil/

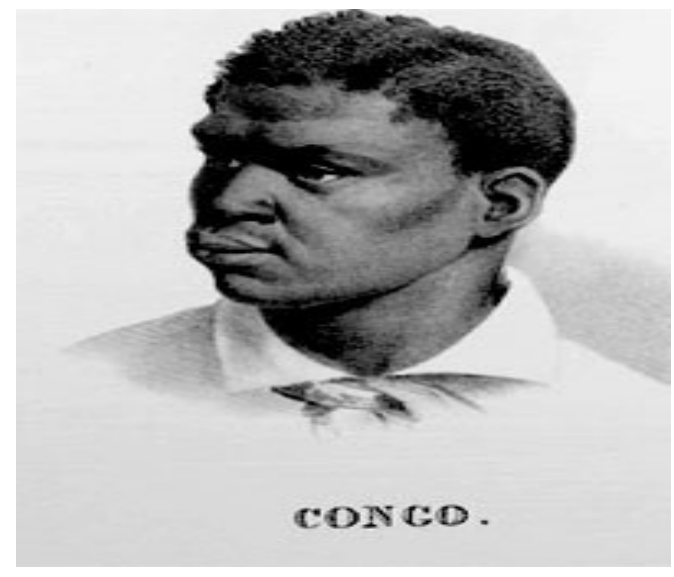

Imagem V: Negro Congo: Litografia Johann Moritz Rugendas, 1835.

Disponível em: http://www.camaracampos.rj.gov.br/tp-cultura/exposicao-escravidao-no-brasil/

As litografias acima, de Johann Moritz Rugendas, com data contemporânea a que Imbert escrevia na Corte, destacam os principais escravizados mencionados e descritos pelo médico. Podemos perceber a riqueza de detalhes ao pintar os cabelos, as narinas, os lábios e os sinais, todos fundamentais de serem observados na hora da compra. Embora nosso objetivo central não seja analisar tais litografias, elas ilustram a importância do conhecimento da origem e do corpo negro, o que poderia ajudar na sua identificação, garantindo, desta forma, "boa compra". Objetivando informar como fazer uma boa escolha, Imbert discorrera informando, com base na origem e local de nascimento dos negros, os que seriam mais úteis aos objetivos dos compradores:

Dossiê Transversos: O Corpo na História e a História do Corpo, Rio de Janeiro, v. 05; n. 05; Ano 02. dez. 2015. 
(...) os negros da Costa do Ouro são reputados os melhores escravos, e são, á excepção dos Minas, estatura regular, fortes, bons trabalhadores, sóbrios, e orgulhosos: o Mina he alto, bem conformado, e de aspecto altivo.

os negros do Baixo Guiné, ou Reino de Benguella, são de estatura baixa, e peito comprido e reforçado. Os escravos deste lugar são de natureza inimigos do trabalho; todavia as negras do Congo merecem estima, porque costumadas no seu paiz a cultivar a terra, são em geral laboriosas (IMBERT, 1839: p. 2).

Em tempos de fim de tráfico, não seria prudente restringir as nações de escravizados que pudessem ser comprados no comércio ilegal, destarte, Imbert (1839: p. 2) reconhecera que "seria por certo supérfluo recommendar aos nossos leitores, que não comprassem negros de nações reconhecidamente más; julgamos porém util indicar-lhes alguns signaes, que podem dar a conhecer os defeitos que se encontrão entre os negros de todos os paizes”. E continuou, listando cinco características físicas - o biológico - todas relacionadas às enfermidades ou falha moral, que deveriam impreterivelmente ser observadas pelos compradores:

1․․ Cabellos encrespados em demasia, testa pequena, ou baixa, olhos encovados, e orelhas grandes, denotão ordinariamente máo caracter;

2‥ Nariz demasiado chato, e ventas mui apertadas, são defeitos que incommodão a respiração, porque não permittem a livre entrada, e sahida do ar;

3o. Lingoa comprida mui espessa, ou mui delgada, dentes mal seguros amarellos, ou pretos, demasiados ou mui pouco salientes, gengivas molles de cor livida que sangrão ao menor toque, respiração presa e fetida; são outras tantas imperfeições physicas, que indicão máo estomago, ou a existencia de vicio no sangue;

4‥ Pescoço comprido, com espaduas elevadas mui inclinadas para a frente, e que tornão o peito estreito, e o sternum curto (osso collocado no meio peito), são signaes certos de que os orgãos collocados nesta cavidade se achão em máo estado;

5․ Deve recursar-se todo o negro que tiver as pernas finas, compridas, e os pés chatos, porque taes escravos nunca são fortes, e são muito mais sujeitos do que os outros a ulceras e inchação das pernas, donde provém naturalmente esses tumores incuraveis dos pés, que desenvolvem frequentemente a elephancia, molestia hedionda (...) (IMBERT, 1839: 2-3).

O autor determina, por meio do saber médico, as características desejáveis e indesejáveis que o negro deveria ter e, principalmente, que precisariam ser observadas pelo comprador, visto que, assim, o escravizado apresentaria "as condições mais favoraveis à saude, e aos serviços penosos que delle se esperão" (1839: p. 3).

\section{Corpo e Saúde}

Corpo saudável poderia significar maior lucro, mão de obra disponível para os árduos trabalhos nas fazendas distantes dos socorros da medicina praticada na Corte, sendo portanto, uma das preocupações de Jean-Baptiste Alban Imbert. Ainda que o comprador fosse um excelente observador, e adquirisse um negro seguindo a todas as instruções do médico, não 
significava dizer que o escravizado estaria livre de desenvolver ou adquirir enfermidades que o impossibilitariam de trabalhar por pequenos ou longos períodos, ou, mesmo, ocasionar óbito. Em qualquer uma dessas hipóteses, perdia-se uma propriedade de alto custo. Nesse sentido, conhecer o corpo negro, escravizado, com seus defeitos, qualidades, bem como sua origem, era fundamental para a avaliação realizada nos diferentes mercados ou entre particulares.

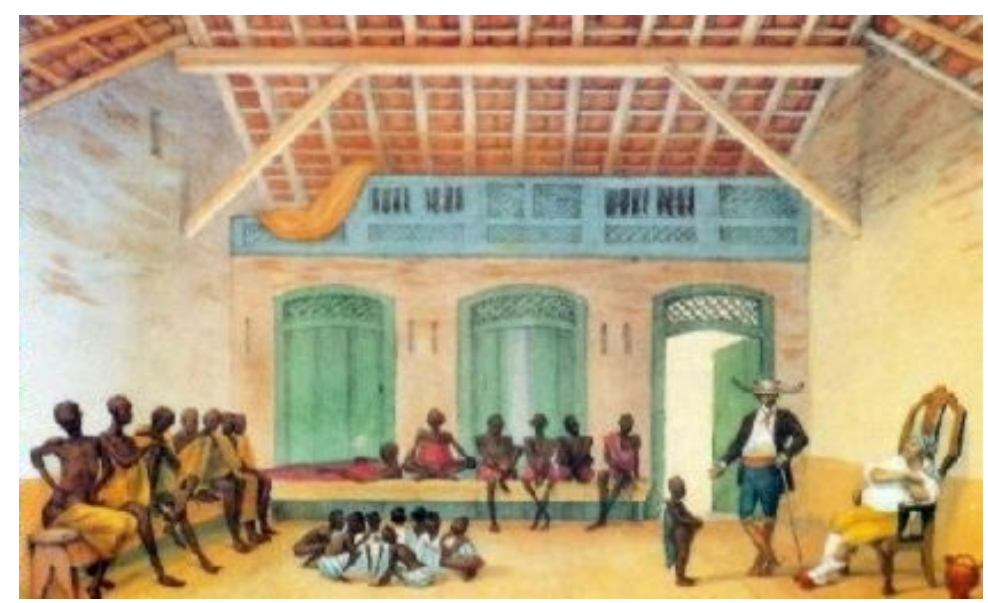

Imagem VI: Mercado na Rua do Valongo. Jean-Baptiste Debret. Disponível em: http://revistaescola.abril.com.br/fundamental-2/africanos-foram-escravizados-brasil-646493.shtml

Mary Karasch, estudando a vida dos escravos no Rio de Janeiro na primeira metade do século XIX, constata o grande índice de mortalidade dos escravizados, informando que em média, entre os anos 1840 e 1849, dois mil e oitocentos eram enterrados por ano (2000: p. 144). $\mathrm{Na}$ região de Vassouras, os números também nos apontam grandes quantitativos, mas proporcionalmente menor. Muitos escravizados enterrados nos cemitérios das fazendas não recebiam o devido registro no livro de óbitos da paróquia, o que não nos permite alcançar os números exatos. As causae mortis eram variadas na Freguesia de Nossa Senhora da Conceição de Vassouras: infecto-parasitárias, sistema circulatório, sistema nervoso e neuropsiquiátrico e sistema digestivo eram as mais significativas. As que tiveram como menção "causas mal definidas", no entanto, superam as demais quantitativamente, provavelmente pela falta de um cirurgião na maioria das fazendas, para atestar a causa mortis.

As moléstias eram, de fato, um problema considerável. Os escravizados que chegavam doentes ao porto eram devidamente afastados dos demais:

Cada navio que chegava ao porto do Rio carregado de escravos deveria primeiro ser vistoriado pelo médico da Saúde; caso se constatasse haver doentes, estes deveriam ser enviados para a quarentena em uma das ilhas da baía de Guanabara; após a sua liberação, deviam desembarcar na Alfândega, a fim de serem registrados, pagarem as taxas etc., e imediatamente depois serem enviados para o Valongo. Assim se deu até o fim do tráfico negreiro (PEREIRA, 2007: p. 75). 
As tentativas de minimizar as perdas eram muitas, principalmente durante o tráfico ilegal, realizado após 1831. Destarte, desenvolver técnicas para alcançar tal fim era valioso e, nesse sentido, a medicina era, sem dúvida, uma estratégia a ser utilizada. O saber médico sobre o corpo escravizado poderia ajudar na compra, como também intervir em casos de doenças. Imbert, ao escrever sobre as moléstias dos negros, pensava o conjunto, viabilizando tratamento e cura por meio da intervenção do conhecimento do corpo, possível somente nessa ciência.

O capítulo segundo, "Dos cuidados geraes de que os doentes devem ser objecto", Imbert sublinha a "obrigação" de prestar apoio, assistência e socorro aos enfermos, pois um doente seria:

[...] durante sua enfermidade, hum ente apartado da sociedade de que elle he membro, e esta rigorosamente deve, directa ou indirectamente, interessar-se por elle, e prestar-lhe cuidados tão assíduos, como illustrados: faltar pois a hum dever tão sagrado he, a nosso ver, hum crime de lesa humanidade, e todo o individuo, que soportasse frio, silencioso, e insensivel diante de hum ente, que padece, ainda sendo seu mais cruel inimigo, mereceria ser taxado certamente de ter abjurado o mais nobre dos sentimentos, com que a natureza nos tem dotado, o amor do próximo [...] (IMBERT, 1839: p. 4).

Escrevendo em tempos de tráfico ilegal e num Império onde a religião Católica era a oficial, o médico lança mão desse artifício. Afinal, o corpo escravizado não é igual ao corpo branco, do senhor, do proprietário, mas quando doente deveria receber os cuidados necessários. Dessa forma, não prestar os devidos socorros a um doente seria faltar a um dever sagrado, ou mais, teria "abjurado o mais nobre dos sentimentos, com que a natureza nos tem dotado, o amor do próximo" (1839: p. 4), um dos dez mandamentos do Novo Testamento. Como, contudo, atender a um número significativo de escravos em fazendas tão distantes da Corte imperial, onde estavam os médicos? Estes, que mesmo naquele local dito "privilegiado", eram poucos?

Dados do recenseamento de 1872 demonstram o ínfimo quantitativo de médicos nas regiões do Vale do Paraíba Fluminense: 22 na Paróquia de Conceição, 10 em Pati, 4 em Ferreiros e 4 em Sacra Família. Sublinhamos que esses dados são relativos ao final do século XIX, quando o número de médicos formados nas Faculdades de Medicina do Rio de Janeiro e da Bahia já havia mais do que duplicado, se comparado com o do início do mesmo século. Nesse contexto, como a população mais pobre e a escravizada eram socorridas em casos de moléstias simples ou graves?

Durante a vigência da Fisicatura-mór, os barbeiros ou sangradores ${ }^{9}$ atuavam nas cidades e também nos campos. Para a região de Vassouras, a partir da análise de inventários post mortem

9 Sobre o funcionamento da Fisicatura e as cartas concedidas às diferentes artes de curar e suas hierarquias, ver: PIMENTA, Tânia Salgado. Terapeutas populares e instituições médicas na primeira metade do século XIX. In: CHALHOUB, Sidney et al. (org.). Artes e Ofícios de Curar no Brasil. Campinas, SP: Editora da Unicamp, 2003.

Dossiê Transversos: O Corpo na História e a História do Corpo, Rio de Janeiro, v. 05; n. 05; Ano 02. dez. 2015. 
de proprietários, foi possível identificar, na década de 1840, escravos descritos como "barbeiro", concernentes às artes de curar entre os do gênero masculino; nenhuma escravizada teve ofício destinado à cura mencionado. Nos anos a partir da década de 1850, as fontes nos apresentaram escravizados "barbeiros", "enfermeiros" e "servente de enfermaria”; e escravizadas "enfermeira" e "parteira”. Ambas dedicavam-se aos cuidados com o corpo doente, ou, eram responsáveis pelas escravizadas na hora do parto (VIANA, 2009: p. 41-45).

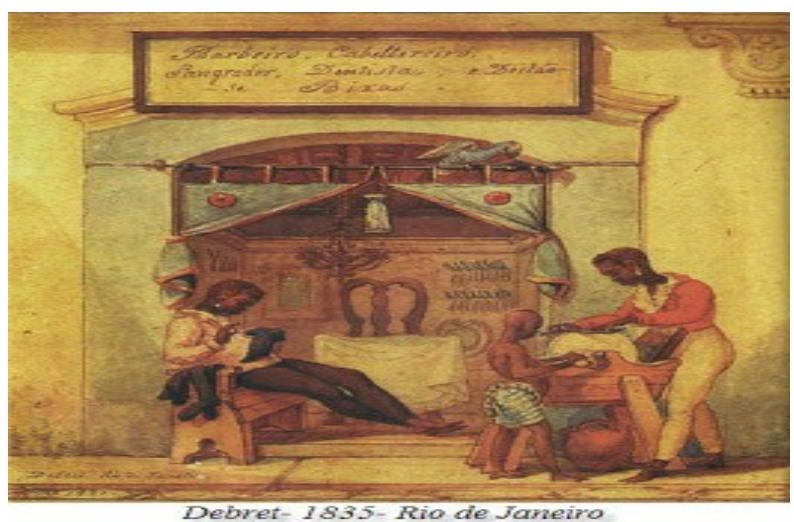

Imagem VII: Loja de barbeiro.

Disponível em: http://stravaganzastravaganza.blogspot.com.br/2011/05/medicina-no-brasil-colonial.html

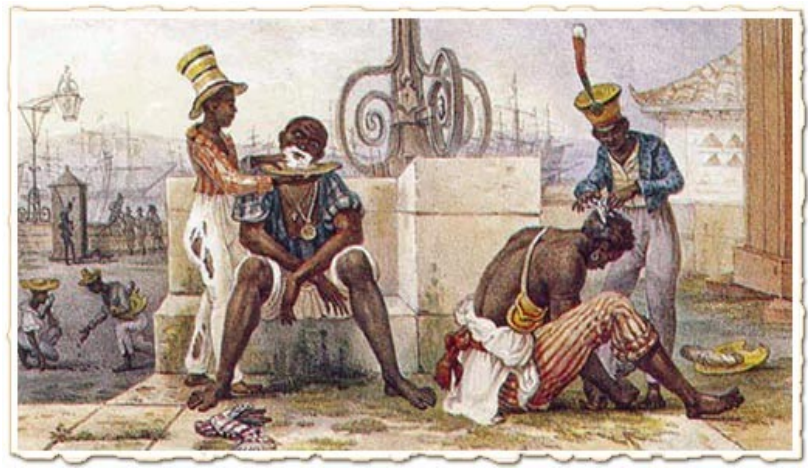

Imagem VIII: Escravos exercendo o ofício de barbeiro. Debret.

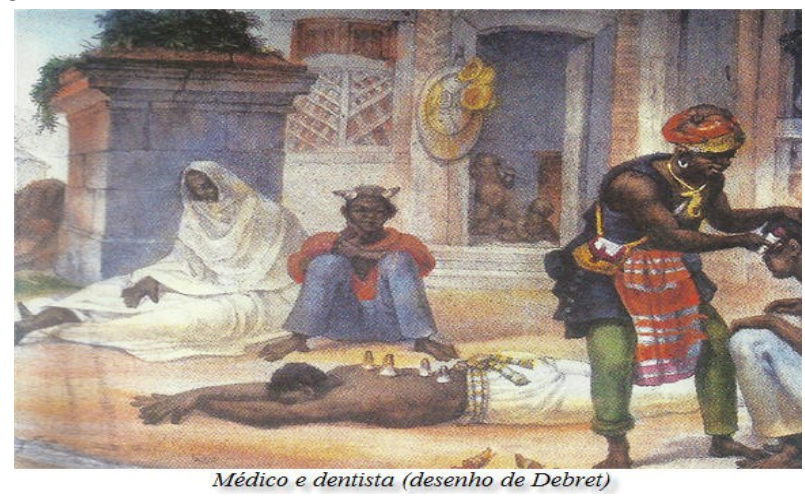

Imagem IX: Sangradores.

Disponível em: http://stravaganzastravaganza.blogspot.com.br/2011/05/medicina-no-brasil-colonial.html

Dossiê Transversos: O Corpo na História e a História do Corpo, Rio de Janeiro, v. 05; n. 05; Ano 02. dez. 2015. 
O corpo escravizado, por meio de uma das possíveis histórias a serem contadas, demonstra a relevância do saber médico sobre ele na vigência do Império do Brasil. Este saber, uma estratégia utilizada para garantir mão de obra saudável pelo maior tempo possível, tentava maximizar a vida útil dos escravizados, preservando-a. Uma alternativa possível às práticas utilizadas para burlar a lei de 1831 .

Preservar a mão de obra poderia significar utilizá-la nas tarefas mais lucrativas, neste caso específico, nas grandes plantações de café. Refletindo sobre "a ação política desenvolvida com a finalidade de alcançar uma restauração", Ilmar de Mattos (2004: p. 17), destaca “a estreita articulação entre as políticas de mão-de-obra e de terras, destacando a necessidade de "poupar a escravidão' e o tráfico interno de escravos”. Nessa perspectiva, destacamos a importância dos manuais médicos de uma forma geral, e o de Jean-Baptiste Alban Imbert de modo específico, como relevantes para a sobrevivência nas fazendas. Nessa história, o conhecimento e o cuidado com o corpo biológico e escravizado eram elementos fundamentais para a manutenção econômica do Império do Brasil no início do século XIX. E como estratégia, a medicina, era relevante para que o saber das artes de curar pudesse alcançar as distantes fazendas em tempos de fim de tráfico transatlântico.

\section{Fonte:}

IMBERT, J.B.A. Manual do Fazendeiro ou Tratado Doméstico sobre as enfermidades dos Negros. 2a․ ed. Rio de Janeiro: Typographia Nacional, 1839.

\section{Referências Bibliográficas:}

ARAUJO, Carlos da Silva. Fatos e Personagens da História da Medicina e da Farmácia no

Brasil. Rio de Janeiro: Editora Continente, 1979.

CHALHOUB, Sidney. A força da Escravidão: ilegalidade e costume no Brasil oitocentista. 1ª . ed. São Paulo: Companhia das Letras, 2012.

FOUCAUlT, Michel. Vigiar e Punir: nascimento da prisão. Petrópolis, RJ: Editora Vozes, 2011. Microfisica do Poder. Rio de Janeiro: Edições Graal, 1979.

GOMES, Flávio dos Santos. Histórias de quilombolas: mocambos e comunidades de senzalas no Rio de Janeiro, século XIX. São Paulo: Companhia das Letras, 2006. 
GRAHAM, Sandra Lauderdale. Caetana diz não: histórias de mulheres da sociedade escravista brasileira. São Paulo: Companhia das Letras, 2005.

KARASCH, Mary C. A Vida dos escravos no Rio de Janeiro, 1808-1850. São Paulo: Companhia das Letras, 2000.

MARQUESE, Rafael de Bivar. Feitores do corpo, missionários da mente: senhores, letrados e o controle dos escravos nas Américas, 1660-1860. São Paulo: Companhia das Letras, 2004.

Administração e Escravidão: ideias sobre a gestão da agricultura escravista brasileira. 2‥ ed. São Paulo: Hucitec, 2010.

MATTOS, Ilmar Rohloff de. O Tempo Saquarema. São Paulo: Hucitec, 2004.

PEREIRA, Julio César Medeiros da Silva. À Flor da Terra: o cemitério dos pretos novos no Rio de Janeiro. Rio de Janeiro: Editora Garamond: IPHAN, 2007.

PIMENTA, Tânia Salgado. Terapeutas populares e instituições médicas na primeira metade do século XIX. In: CHALHOUB, Sidney et al. (org.). Artes e Ofícios de Curar no Brasil. Campinas, SP: Editora da Unicamp, 2003.

RODRIGUES, José Carlos. Tabu do corpo. Rio de Janeiro: Editora FIOCRUZ, 2006.

SALLES, Ricardo. E o Vale era o Escravo. Vassouras, séculos XIX. Senhores e escravos no coração do Império. Rio de Janeiro: Civilização Brasileira, 2008.

SAMPAIO, Gabriela dos Reis. Nas Trincheiras da Cura. As diferentes medicinas no Rio de Janeiro Imperial. Campinas, SP: Editora da Unicamp, 2001.

SILVA, Eduardo; REIS, João José. Negociação e Conflito: a resistência negra no Brasil escravista. São Paulo: Companhia das Letras, 1989.

SLENES, Robert W. "Malungu, ngoma vem!": África coberta e descoberta do Brasil. Revista USP, Brasil, n. 12, p. 48-67, fev. 1992. ISNN 2316-9036. Disponível em: 〈http://www.revistas.usp.br/revusp/article/view/25575>. Acesso em: 28 fev 2015.

Na Senzala uma Flor: esperanças e recordações na formação da família escrava. Campinas, SP: Editora da Unicamp, 2011.

STEIN, Stanley. Vassouras: um município brasileiro do café, 1850-1900. Rio de Janeiro: Nova Fronteira, 1990. 
VIANA, Iamara da Silva. Morte escrava e relações de poder em Vassouras (1840-1880): hierarquias raciais, sociais e simbolismos. Dissertação de Mestrado, Rio de Janeiro: Centro de Educação e Humanidades, Universidade do Estado do Rio de Janeiro, 2009.

XAVIER, Regina. Dos males e suas curas: práticas médicas na Campinas oitocentista. In: Chalhoub, Sidney et al. (org). Artes e Ofícios de Curar no Brasil: capítulos de história social. Campinas, SP: Editora da Unicamp, 2003. p. 342-343.

\section{Como citar:}

VIANA, Iamara da Silva. Corpos escravizados: que histórias contam?. Revista Transversos. “Dossiê: O Corpo na História e a História do Corpo”. Rio de Janeiro, Vol. 05, nํ. 05, pp. 107123, Ano 02. dez. 2015. Disponível em: <http://www.e-publicacoes.uerj.br/index.php/trans versos>. ISSN 2179-7528. DOI: 10.12957/transversos.2015.19800. 